\title{
Enhancing and Sustaining AMG 009 Dissolution from a Matrix Tablet Via Microenvironmental pH Modulation and Supersaturation
}

\author{
Mingda Bi, ${ }^{1,4,5}$ Ali Kyad, ${ }^{2}$ Yuan-Hon Kiang, ${ }^{3}$ Fernando Alvarez-Nunez, ${ }^{1}$ and Francisco Alvarez ${ }^{1}$
}

Received 7 February 2011; accepted 23 August 2011; published online 13 September 2011

\begin{abstract}
The objective of this study was to investigate the combined effect of $\mathrm{pH}$ modifiers and nucleation inhibitors on enhancing and sustaining the dissolution of AMG 009 tablet via supersaturation. Several bases and polymers were added as $\mathrm{pH}$ modifiers and nucleation inhibitors, respectively, to evaluate their impact on the dissolution of AMG 009 tablets. The results indicate that sodium carbonate, among the bases investigated, enhanced AMG 009 dissolution the most. HPMC E5 LV, among the nucleation inhibitors tested, was the most effective in sustaining AMG 009 supersaturation. The release of AMG 009 went from $4 \%$ for tablets which did not contain both sodium carbonate and HPMC E5 LV to $70 \%$ for the ones that did, resulting in a 17.5 -fold increase in the extent of dissolution. The effect of compression force and disintegrant on the dissolution of tablets were also evaluated. The results indicate that compression force had no effect on AMG 009 release. The addition of disintegrating agents, on the other hand, decreased the dissolution of AMG 009.
\end{abstract}

KEY WORDS: enhancing; microenvironmental pH; nucleation inhibitor; $\mathrm{pH}$ modifier; precipitation; supersaturation; sustaining; tablet dissolution.

\section{INTRODUCTION}

The oral bioavailability of a drug is mainly a function of its dissolution, stability in gastrointestinal fluids, permeation into the systemic circulation, and metabolic stability. For a low soluble compound, its dissolution is often more ratelimiting than its ability to cross the intestinal mucosa (1); therefore, it is important to enhance drug dissolution in order to increase its bioavailability. The dissolution of a drug is a function of the drug's solubility in the diffusion layer $(2,3)$. For weak acidic/basic drugs, this solubility can be a function of the $\mathrm{pH}$ of the diffusion layer.

A number of studies (4-8) have been performed in the past, especially in the area of controlled release in which organic or inorganic acids or bases, used as $\mathrm{pH}$ modifiers, were added to formulations to control the $\mathrm{pH}$ of the environment immediately surrounding the solid. Through this control of the microenvironment of the dosage form,

\footnotetext{
${ }^{1}$ Formulation Group, Pharmaceutical R\&D, Amgen Inc., Thousand Oaks, California 91320, USA.

${ }^{2}$ Analytical R\&D, Amgen Inc., Thousand Oaks, California 91320, USA.

${ }^{3}$ Preformulation Group, Pharmaceutical R\&D, Amgen Inc., Thousand Oaks, California 91320, USA.

${ }^{4}$ One Amgen Center Drive, Thousand Oaks, California 91320, USA.

${ }^{5}$ To whom correspondence should be addressed. (e-mail: mbi@ amgen.com)
}

$\mathrm{pH}$-independent release has been achieved for basic or acidic drugs in the gastrointestinal tract where the $\mathrm{pH}$ can vary from 1.0 to 7.4. These studies demonstrated that the $\mathrm{pH}$ of the microenvironment (i.e., $\mathrm{pH}$ of diffusion layer), and therefore the dissolution of weak acidic and basic drugs, can be modulated. Because of this finding, the dissolution of poorly soluble weak acidic and basic drugs in both immediate-release $(9,10)$ and controlled-release (11-17) dosage forms has been successfully enhanced or retarded by the application of the concept of microenvironmental $\mathrm{pH}$ modulation.

The $\mathrm{pH}$ of the microenvironment is critical for increasing the transient solubility of poorly soluble weak acidic and basic drugs in the diffusion layer and, therefore, their dissolution rate. The $\mathrm{pH}$ of the bulk dissolution medium, on the other hand, is quite different from that of the diffusion layer. $\mathrm{A} \mathrm{pH}$ gradient may also exist within the diffusion layer itself where the $\mathrm{pH}_{h=0}(\mathrm{pH}$ value at phase boundary $h=0$, where $h$ is the thickness of diffusion layer) and $\mathrm{pH}_{h=h}(\mathrm{pH}$ value at phase boundary $h=h$ ) are different $(18,19)$. As a result, the dissolved drug at $\mathrm{pH}_{h=0}$ may become supersaturated with respect to its solubility at $\mathrm{pH}_{h}=h$ and the bulk dissolution medium, causing it to precipitate out when it diffuses from phase boundary $h=0$ to $h=h$ and further into the bulk dissolution medium. These $\mathrm{pH}$ differences may compromise the overall rate and extent of the dissolution of the drug.

It is hypothesized that adding nucleation inhibitors in addition to $\mathrm{pH}$ modifiers into the tablet might be a better way 
to enhance the dissolution rate and sustain the extent of dissolution of poorly soluble weak acidic and basic drugs by preventing the precipitation of supersaturated drugs in the diffusion layer and bulk dissolution medium.

AMG 009 is indicated for the treatment of inflammatory diseases. It is a BCS class II compound with an intrinsic solubility of $0.6 \mu \mathrm{g} / \mathrm{mL}$. Its chemical structure is shown in Fig. 1. The objective of this study was to use AMG 009, a poorly soluble weak acidic drug, as the model compound to investigate the combined effect of $\mathrm{pH}$ modifiers and nucleation inhibitors on enhancing AMG 009 tablet dissolution. The potential impact of other formulation/process variables (e.g., disintegrant and compression forces) on AMG 009 release from the tablet was also evaluated.

\section{MATERIALS}

\section{Selected pH Modifiers}

Sodium carbonate $\left(\mathrm{Na}_{2} \mathrm{CO}_{3}\right)$, sodium bicarbonate $\left(\mathrm{NaHCO}_{3}\right)$, tromethamine (Tris, $\left.\left(\mathrm{HOCH}_{2}\right)_{3} \mathrm{CNH}_{2}\right)$, sodium acetate $\left(\mathrm{CH}_{3} \mathrm{COONa}\right)$, sodium phosphate $\left(\mathrm{Na}_{2} \mathrm{HPO}_{4}\right)$, and sodium citrate dihydrate $\left(\mathrm{Na}_{3} \mathrm{C}_{6} \mathrm{H}_{5} \mathrm{O}_{7} \cdot 2 \mathrm{H}_{2} \mathrm{O}\right)$ were purchased from EMD Chemicals Inc., NJ, USA. All materials were screened through a no. 40 mesh screen before use.

\section{Selected Nucleation Inhibitors}

HPMC K100 LV and HPMC E5 LV were purchased from Dow Chemical Company, Michigan, USA; Plasdone K-17 (PVP K17) was from International Special Products, NJ, USA. All materials were used as received.

\section{METHODS}

\section{Solubility Studies}

An excess amount of AMG 009 was added to water, $0.01 \mathrm{~N} \mathrm{HCl}$, and $50 \mathrm{mM}$ buffers (i.e., sodium citrate, sodium phosphate, or sodium carbonate) of targeted $\mathrm{pH}$ to give a suspension in 4-mL glass vials. These vials were rotated on a specimen tube rotator (Glas-Col, LLC, IN, USA) for $48 \mathrm{~h}$ to achieve equilibration at room temperature. After $48 \mathrm{~h}$, all samples were filtered using a $0.45-\mu \mathrm{m}$ PTFE filter, which has been tested to provide $>99 \%$ recovery of AMG 009 after filtration. An aliquot was taken from each filtrate for HPLC analysis. The remaining filtrate was used to measure the final $\mathrm{pH}$. The chromatography was carried out on an Agilent HP 1100, equipped with the multi-wavelength detector (MWD detector, G1365A) and Chromeleon ${ }^{\mathrm{TM}}$ software for data analysis. The mobile phase consisted of (A) $0.1 \%$ trifluoroacetic acid $/ 2 \%$ acetonitrile/97.9\% water $(v / v)$ and (B) $0.1 \%$

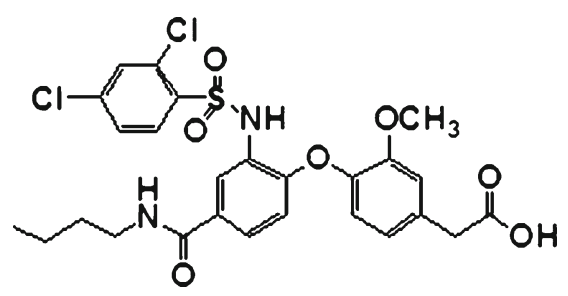

Fig. 1. Chemical structure of AMG 009 trifluoroacetic acid/98\% acetonitrile/1.9\% water $(v / v)$. A gradient program (mobile phase A from $90 \%$ to $10 \%$ for the first 5 min followed by $10 \%$ mobile phase A for 4 min and then $90 \%$ mobile phase $\mathrm{A}$ in $1 \mathrm{~min}$ ) was used to elute AMG 009. The separation was achieved using a Zorbax SB-C18 column $(5 \mu \mathrm{m}, 4.6 \times 150 \mathrm{~mm}$, Agilent Technologies, CA, USA). A flow rate of $1 \mathrm{~mL} / \mathrm{min}$, an injection volume of $20 \mu \mathrm{L}$, ambient column temperature, and run time of $10 \mathrm{~min}$ were employed. Detection was achieved by UV at $225 \mathrm{~nm}$.

\section{Dissolution Studies}

Unless specified, all dissolution studies were conducted in $900 \mathrm{~mL}$ of $0.01 \mathrm{~N} \mathrm{HCl}$ containing $0.033 \%$ HPMC E5 LV at $37^{\circ} \mathrm{C}$ using USP Apparatus II at an agitation rate of $50 \mathrm{rpm}$. The purpose of adding HPMC E5 LV in some experiments is to enhance the discrimination of the dissolution method. The dissolution samples were analyzed using the Opt-Diss Fiber Optic UV system (Distek Inc., NJ, USA). This UV Fiber Optic system was equipped with a multichannel CCD spectrometer (210-400 nm). Fiber-optic arch probes, which connect individually to the CCD spectrometer, were calibrated and inserted directly into the dissolution vessels to measure real-time dissolution at $225 \mathrm{~nm}$. The cumulative percentage of drug release was calculated in real time with the Opt-Diss software. The mean of two determinations was used in the data analysis. The dissolution data of placebo tablets were also collected and subtracted from those of active tablets.

\section{Manufacture of Control and Test Tablets}

Tables I and II show the composition of control and test tablets. Control tablets do not contain $\mathrm{pH}$ modifiers. Test tablets contain $\mathrm{pH}$ modifiers, nucleation inhibitors, or a combination thereof. Control and test tablets were manufactured at $5 \mathrm{~g}$ per batch via a direct compression process. AMG 009 was mixed with all ingredients in a $50-\mathrm{mL}$ glass bottle using a Turbula mixer (GlenMills Inc., NJ, USA) for $3 \mathrm{~min}$, and then the mixture was screened through a no. 40 mesh screen. The screened mixture was then put back into the bottle with a magnetic stir bar. The blend was then further mixed on a magnetic stir plate for approximately $5 \mathrm{~min}$ at $400 \mathrm{rpm}$. The resulting blends were compressed into tablets by a semi-automatic Carver Press (Carver Inc., IN, USA) at $4.89 \mathrm{kN}$ using 7-mm round concave tooling.

Table I. Compositions of Control Tablet Formulation

\begin{tabular}{lcc}
\hline Ingredients & $\begin{array}{l}\text { Composition } \\
(\%, w / w)\end{array}$ & $\begin{array}{l}\text { Milligrams/ } \\
\text { tablet }\end{array}$ \\
\hline AMG 009 Micronized & 20.00 & 25.00 \\
Lactose monohydrate, Fast & 39.50 & 49.37 \\
$\quad$ Flo 316 & & \\
Microcrystalline cellulose, & 25.00 & 31.25 \\
$\quad$ Avicel PH102 & 15.00 & 18.75 \\
HPMC E5 LV & 0.50 & 0.63 \\
Magnesium stearate & 100.00 & 125.00 \\
Total & & \\
\hline
\end{tabular}


Table II. Compositions of Test Tablet Formulations

\begin{tabular}{|c|c|c|c|c|c|c|c|c|c|c|}
\hline \multirow[b]{2}{*}{ Ingredients } & \multicolumn{10}{|c|}{ Formulation composition $(\%, w / w)$} \\
\hline & F I & F II & F III & F IV & F V & F VI & F VII & F VIII & F IX & F X \\
\hline AMG 009 Micronized & 20.0 & 20.0 & 20.0 & 20.0 & 20.0 & 20.0 & 20.0 & 20.0 & 20.0 & 20.0 \\
\hline Lactose monohydrate, Fast Flo 316 & 43.6 & 33.6 & 32.0 & 38. & 38.6 & 38.6 & 28.57 & 28.6 & 27.0 & 23.6 \\
\hline Microcrystalline cellulose, Avicel PH102 & 25.0 & 25.0 & 25.0 & 25.0 & 25.0 & 25. & 25.0 & 25.0 & 25.0 & 25.0 \\
\hline HPMC K100 LV & - & 10.0 & 10.0 & - & 5.0 & - & - & 15.0 & 15.0 & 15.0 \\
\hline Magnesium stearate & 0.5 & 0.5 & 0.5 & 0.5 & 0.5 & 0.5 & 0.5 & 0.5 & 0.5 & 0.5 \\
\hline $\mathrm{Na}_{2} \mathrm{CO}_{3}$ & 10.9 & 10.9 & - & 10.9 & 10.9 & 10.9 & 10.9 & 10.9 & - & 10.9 \\
\hline Tris & - & - & 12.5 & - & - & - & - & - & 12.5 & - \\
\hline PVP K17 & - & - & - & 5.0 & - & - & - & - & - & - \\
\hline HPMC E5 LV & - & - & - & - & - & 5.0 & 15.0 & - & - & - \\
\hline Sodium Croscarmellose & - & - & - & - & - & - & - & - & - & 5.0 \\
\hline Total & 100.0 & 100.0 & 100.0 & 100.0 & 100.0 & 100.0 & 100.0 & 100.0 & 100.0 & 100.0 \\
\hline Weight/tablet (mg) & 125.0 & 125.0 & 125.0 & 125.0 & 125.0 & 125.0 & 125.0 & 125.0 & 125.0 & 125.0 \\
\hline
\end{tabular}

\section{RESULTS AND DISCUSSION}

The $\mathrm{pH}$ solubility profile of AMG 009 is shown in Fig. 2. Intrinsic solubility of the unionized drug is very low $(0.6 \mu \mathrm{g} / \mathrm{mL})$. Solubility increases with $\mathrm{pH}$, reaching $4.7 \mathrm{mg} / \mathrm{mL}$ at $\mathrm{pH}$ 8.3. These facts indicate that a strong basic $\mathrm{pH}$ modifier is needed in the tablet to increase the $\mathrm{pH}$ of the microenvironment, and thus the solubility, resulting in an increased dissolution of AMG 009.

Figure 3 shows the dissolution profiles of the control tablets and test tablets of formulations I-III. The results shown in Fig. 3 indicate that adding a $\mathrm{pH}$ modifier (formulation I) to the tablet can enhance the dissolution, but the effect could not be sustained due to the precipitation of AMG 009, as a result of supersaturation, in the bulk dissolution medium. Adding both a $\mathrm{pH}$ modifier and a nucleation inhibitor to the tablets (formulations II-III) appears to enhance and sustain AMG 009 dissolution simultaneously.

However, the results obtained in Fig. 3 indicate that the differences between sodium carbonate and Tris in enhancing the extent of AMG 009 dissolution could not be differentiated. Theoretically, sodium carbonate should be more effective than Tris in enhancing dissolution because sodium carbonate $\left(\mathrm{p} K_{\mathrm{a}}=10.3\right)$ can provide a higher microenvironmental $\mathrm{pH}$ than Tris $\left(\mathrm{p} K_{\mathrm{a}}=8.3\right)$ does, resulting in more AMG 009 to be solubilized and leading to a higher extent of dissolution. However, it is unknown whether the extra amount of AMG 009 solubilized, as a result of the higher

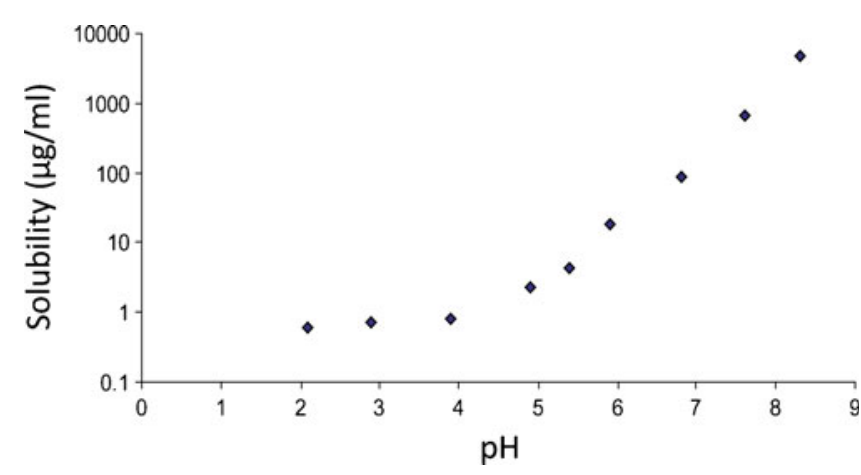

Fig. 2. $\mathrm{pH}$ solubility profile of AMG 009 microenvironment $\mathrm{pH}$ created by sodium carbonate, was sustained. In order to investigate this, several commonly used nucleation inhibitors were evaluated below.

Dissolution studies of formulations IV-VIII were conducted to (1) compare the effectiveness of some commonly used nucleation inhibitors and (2) find the practical concentration range of the most effective nucleation inhibitor in the formulation. Figure 4 shows the dissolution profiles of tablets manufactured with formulations IV-VIII in $0.01 \mathrm{~N} \mathrm{HCl}$ dissolution medium. The results presented in Fig. 4 indicate that HPMC E5 LV is most effective in enhancing AMG 009 dissolution and that its effectiveness increases with its concentration in the formulation.

Because of the above finding, dissolution studies of formulations VIII-IX were conducted by adding HPMC E5 LV $(0.033 \%, w / v)$ to $0.01 \mathrm{~N} \mathrm{HCl}$ dissolution medium to further understand the impact of sodium carbonate versus Tris on AMG 009 dissolution. The results shown in Fig. 5 indicate that sodium carbonate is indeed more effective than Tris in enhancing AMG 009 dissolution as a result of its high $\mathrm{p} K_{\mathrm{a}}$ value of 10.3 versus 8.3 of Tris. The high $\mathrm{p} K_{\mathrm{a}}$ value of sodium carbonate results in a solution $\mathrm{pH}$ of 11.5 versus 10.5

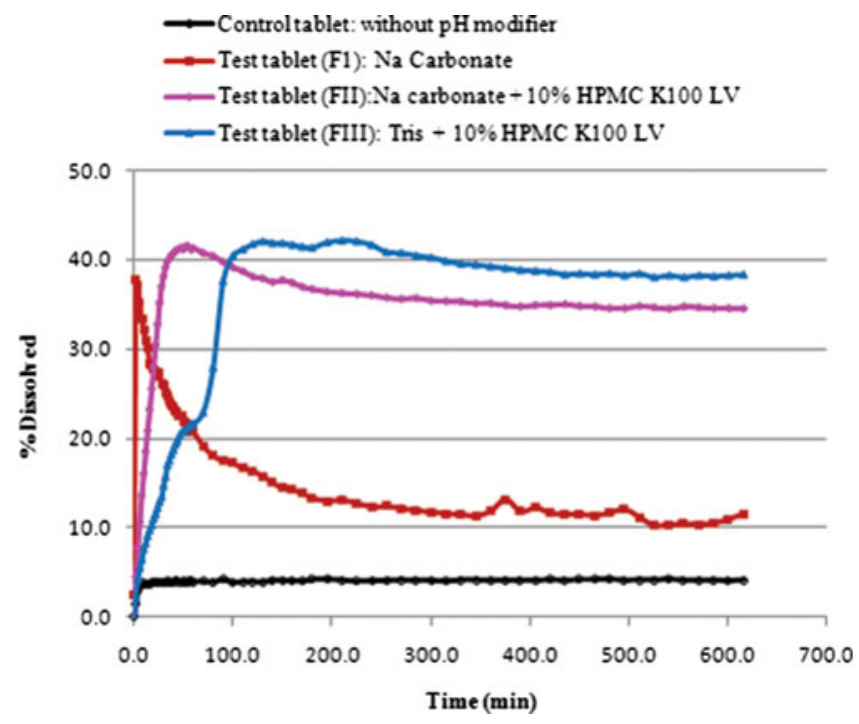

Fig. 3. Tablet dissolution profiles in $900 \mathrm{~mL}$ of $0.01 \mathrm{~N} \mathrm{HCl}$ using USP Apparatus II 


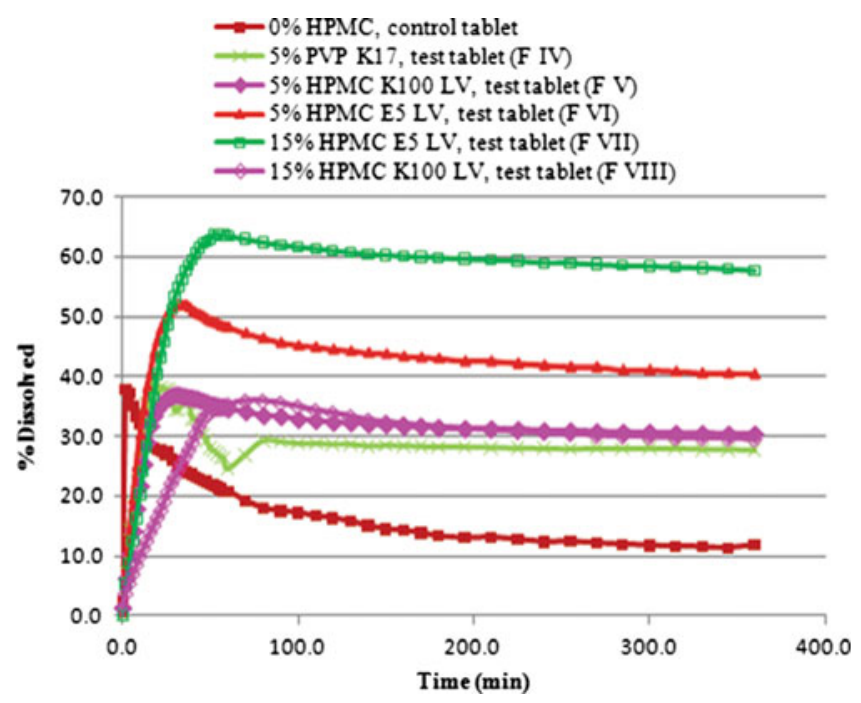

Fig. 4. Tablet dissolution profiles in $900 \mathrm{~mL}$ of $0.01 \mathrm{~N} \mathrm{HCl}$ using USP Apparatus II

of Tris solution, which led to more AMG 009 to be solubilized in the diffusion layer according to the $\mathrm{pH}$ solubility study presented in Fig. 2. The extra amount of AMG 009 dissolved was then sustained by the most effective nucleation inhibitor HPMC E5 LV in the $0.01 \mathrm{~N} \mathrm{HCl}$ dissolution medium.

Other $\mathrm{pH}$ modifiers, such as sodium bicarbonate $\left(\mathrm{p} K_{\mathrm{a}}=6.3\right)$, sodium phosphate $\left(\mathrm{p} K_{\mathrm{a}}=7.2\right)$, sodium citrate $\left(\mathrm{p} K_{\mathrm{a}}=5.4\right)$, and sodium acetate $\left(\mathrm{p} K_{\mathrm{a}}=4.8\right)$ with a solution $\mathrm{pH}$ of $7.96,9.21,8.60$, 8.82, respectively, had little effect on enhancing AMG 009 dissolution; therefore, their plots were not shown. In summary, the results obtained in the experiments described above indicate that the studied nucleation inhibitor does not only to sustain AMG 009 dissolution but they also help differentiate the effectiveness of $\mathrm{pH}$ modifiers. It can be deduced from the comparison of the dissolution profiles of control tablets with those of the test tablets that the combination of sodium carbonate and nucleation inhibitors was very effective in enhancing the release of AMG 009. This is evidenced by the enhancement of the release of AMG 009 by sodium carbonate and HPMC E5 LV from 4\% in the control tablets that did not contain them to $70 \%$ in tablets that did. Although none of the

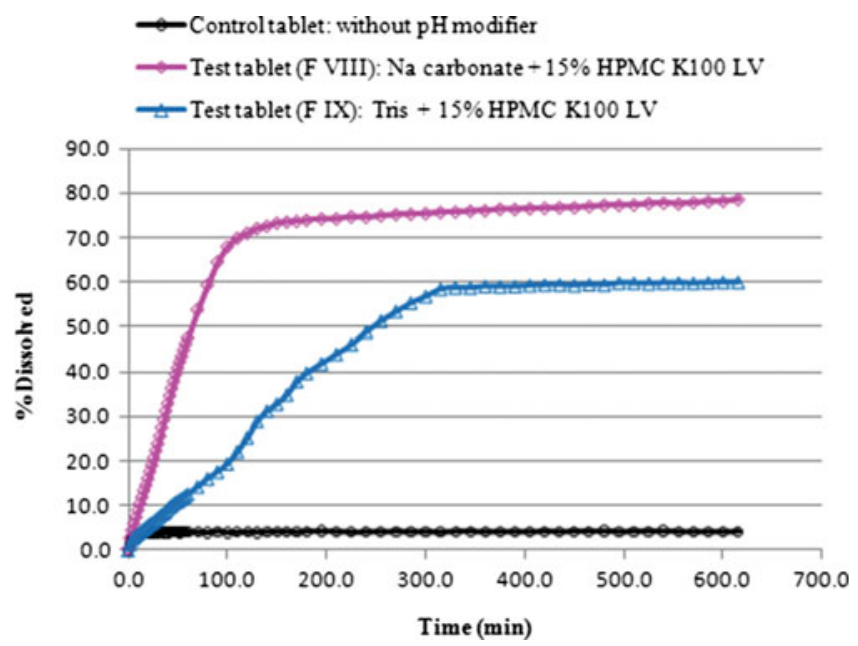

Fig. 5. Tablet dissolution profiles in $900 \mathrm{~mL}$ of $0.01 \mathrm{~N} \mathrm{HCl}$ containing $0.033 \%$ HPMC E5 using USP Apparatus II

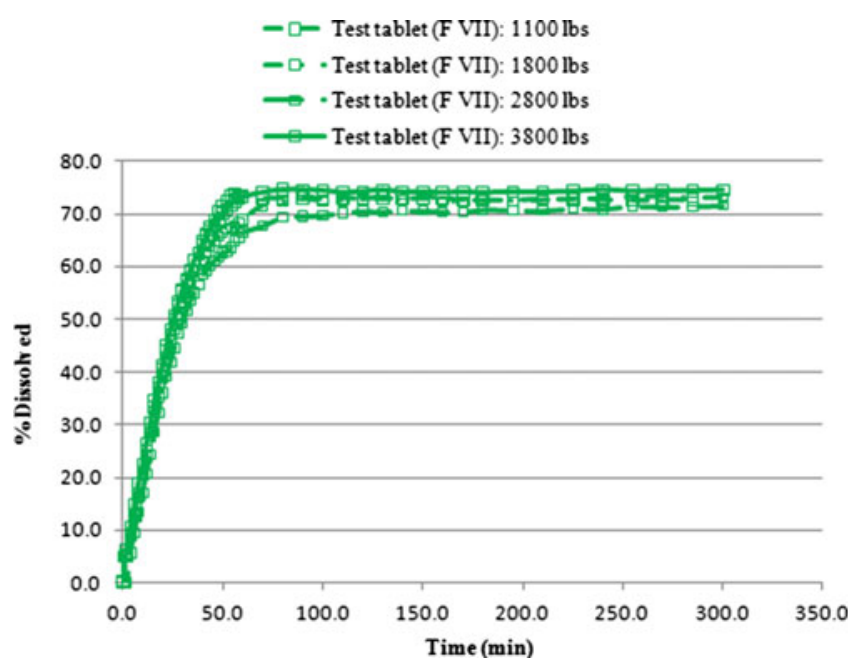

Fig. 6. Tablet dissolution profiles in $900 \mathrm{~mL}$ of $0.01 \mathrm{~N} \mathrm{HCl}$ containing $0.033 \%$ HPMC E5 using USP Apparatus II

tablet formulations released $100 \%$ AMG 009 in the above studies, the assay of tablet formulations indicated that they are from $98.1 \%$ to $99.8 \%$ of claim value. This indicates that the formulation can be further optimized to enhance AMG 009 release to $100 \%$ by adding more sodium carbonate and HPMC E5 in the formulation. However, this is beyond the scope of this study.

Previous studies (20) have indicated that the extent of AMG 009 dissolution increased with the concentration of HPMC E5 LV in the dissolution medium. A similar correlation was not observed with HPMC K100 LV. In the same studies, it was found that the rate of AMG 009 dissolution was independent of HPMC E5 LV concentration in the tablet, but became slower when higher amounts of HPMC K100 LV were added. These findings are consistent with the results shown in Fig. 4. The results presented in Fig. 4 indicate that the extent of AMG 009 dissolution increased with HPMC E5 LV concentration, but the rate was concentration-independent. On the other hand, it was observed from the results obtained in Fig. 4 that the extent of AMG 009 dissolution was independent of HPMC K100 LV concentration and that the rate of dissolution became slower as the HPMC K100 LV concentration

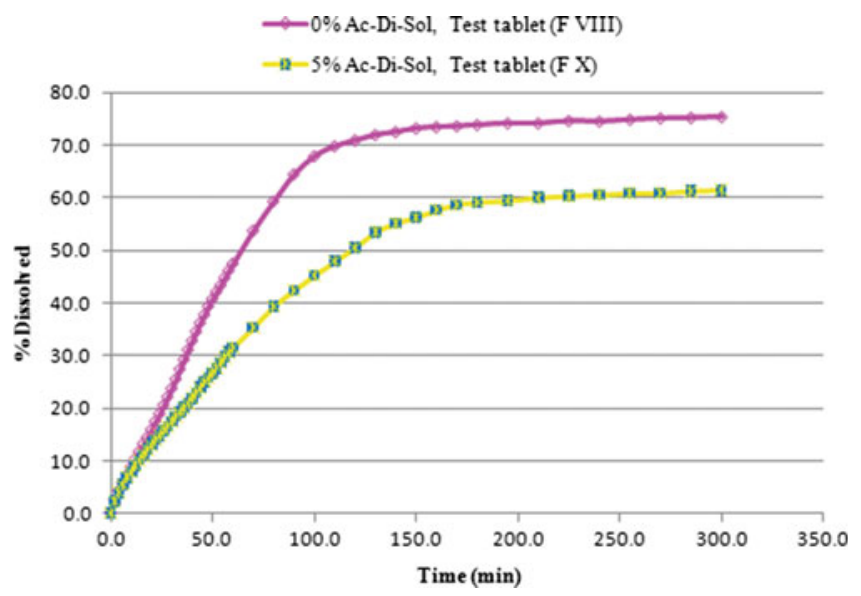

Fig. 7. Tablet dissolution profiles in $900 \mathrm{~mL}$ of $0.01 \mathrm{~N} \mathrm{HCl}$ containing 0.033\% HPMC E5 using USP Apparatus II 
increased in the tablets. The overall information shown in Fig. 4 indicates that both the dissolution rate and the amount dissolved were markedly enhanced when HPMC E5 LV was used. This confirmed the results from the previous studies, further supporting the conclusion that HPMC E5 LV is more effective in enhancing the rate and extent of AMG 009 dissolution. It is, however, plausible that the HPMC K100 LV in the tablet also helped enhance AMG 009 dissolution (20). This is because the higher concentration of HPMC K100 LV inside the tablets probably helped prevent the premature loss of $\mathrm{pH}$ modifiers into the dissolution medium and consequently prevented the loss of their $\mathrm{pH}$ modulation function. HPMC E5 LV in the tablets is hypothesized to function similarly to HPMC K100 LV in that it will help prevent the premature loss of $\mathrm{pH}$ modifiers into the dissolution medium as well as prevent the precipitation of dissolved AMG 009.

It is expected that $\mathrm{pH}$ modifiers, for example sodium carbonate, will dissolve rapidly in an acidic environment, which will lead to the rapid dissolution of AMG 009. The dissolved AMG 009 will partially or completely precipitate out of the diffusion layer if the nucleation inhibitor does not dissolve fast enough to prevent nucleation. On the other hand, it is important to know that the inhibiting power of a nucleation inhibitor is also critical. Therefore, a nucleation inhibitor that dissolves fast and is effective in inhibiting AMG 009 nucleation should be selected. The results shown in Fig. 4 indicate that HPMC E5 LV is much more effective in enhancing AMG 009 dissolution than the other nucleation inhibitors investigated, such as PVP K17 and HPMC K100 LV. It is believed that HPMC E5 LV may have a faster dissolution rate and a stronger inhibiting power than HPMC K100 LV (20); therefore, it can quickly diffuse into the supersaturated diffusion layer and inhibit the precipitation of AMG 009. The average molecular weight of HPMC E5 LV is 10,000 compared with that of HPMC K100 LV which is 26,000. Dissolved HPMC E5 LV should therefore diffuse faster into the bulk dissolution medium along with the dissolved drug than HPMC K100 LV and thus prevent drug nucleation and crystal growth in bulk dissolution medium to further enhance dissolution. PVP K17 might dissolve and diffuse fast, but it lacks inhibiting power, making it less effective in dissolution enhancement. Additional studies are underway to understand from the molecular level why HPMC E5 LV is more effective than other nucleation inhibitors in sustaining AMG 009 supersaturation.

The dissolution of a tablet depends on a number of factors including the $\mathrm{pH}$ of the dissolution medium, disintegration time of the tablet, compression forces used to make the tablet, the particle size of the active pharmaceutical ingredient (API), the API's physical form, and the formulation excipients used. In the test tablet, the API's particle size and physical form are fixed along with the key formulation ingredients, $\mathrm{Na}_{2} \mathrm{CO}_{3}$ and $\mathrm{HPMC}$, and this leads to the $\mathrm{pH}$ of the microenvironment being fixed as well. The effects of disintegration time and compression force on the dissolution of test tablet are, however, unknown.

To study the effects of disintegration time and compression force, formulation VII was compressed at different forces (i.e., from 1,100 to $3,800 \mathrm{lbs}$ ) and the dissolution profiles of the resulting tables were obtained. The results are shown in Fig. 6; they indicate that compression forces, within the studied range, did not have significant effects on the dissolution of the test tablets. Usually, the larger the compression force, the longer the disintegration time (DT). A slower dissolution may be observed for a harder tablet if dissolution is DT-dependent. For the test tablet with $15 \%$ HPMC E5 LV, dissolution is mainly erosion-controlled rather than disintegration-controlled. Therefore, the dissolution of test tablets is independent on the DT, and thus a larger compression force had no effect on their dissolution. It is important to note, however, that the test tablets still perform as an immediate-release dosage form even though $15 \%$ HPMC K100 LV or E5 LV was added into the tablet, and this is confirmed by the observation that all test tablets eroded and disappeared within $50 \mathrm{~min}$ after the dissolution was started.

Figure 7 shows the dissolution profiles of tablets manufactured from formulations VIII and X. The results presented in Fig. 7 indicate that the tablet dissolution was retarded with the addition of a disintegrant, and this can be explained in the following ways. Tablets might swell to some extent as a result of the addition of a disintegrant, leading to more pores and channels being formed in the tablets. This might enhance the loss of the $\mathrm{pH}$ modifier into the dissolution medium. In addition, a more acidic dissolution medium might diffuse into the tablets as a result of swelling of the disintegrant-containing test tablets, and this would neutralize part of the $\mathrm{Na}_{2} \mathrm{CO}_{3}$ in the tablet. As a result, microenvironmental $\mathrm{pH}$ modulation by $\mathrm{Na}_{2} \mathrm{CO}_{3}$ was, thus, partially lost, leading to a decreased AMG 009 dissolution.

\section{CONCLUSIONS}

Several AMG 009 tablet formulations were developed with $\mathrm{pH}$ modifiers and nucleation inhibitors to study their impact on table dissolution. The results obtained showed that tablets containing both sodium carbonate and HPMC E5 LV exhibited an enhanced AMG 009 release of around $70 \%$ in simulated gastric fluid compared with $4 \%$ release in tablets without them. The combination of $\mathrm{pH}$ modifiers and nucleation inhibitors was much more effective in enhancing the dissolution than $\mathrm{pH}$ modifiers alone. Lastly, it was found that adding a disintegrant is detrimental to the dissolution enhancement of test tablets.

\section{REFERENCES}

1. Hörter D, Dressman JB. Influence of physicochemical properties on dissolution of drugs in the gastrointestinal tract. Adv Drug Delivery Rev. 1997;25:3-14.

2. Gibaldi M. Biopharmaceutics and clinical pharmacokinetics. Philadelphia: Lea \& Febiger; 1984.

3. Banker GS, Rhodes CT. Modern pharmaceutics. New York: Marcel Dekker; 1979.

4. Levy G, Leonards JR, Procknal JA. Development of in vitro dissolution tests which correlate quantitatively with dissolution rate-limited drug absorption in man. J Pharm Sci. 1965;54:1719-22.

5. Javaid KA, Cadwallader DE. Dissolution of aspirin from tablets containing various buffering agents. J Pharm Sci. 1972;61:1370-3.

6. Dwight JS. 1972a. Improvements in pharmaceutical compositions. British Patent GB1291281.

7. Dwight JS. 1972b. Improvement in pharmaceutical compositions. British Patent GB1291282.

8. Hata T, Yamaguchi H, Ueda S, Kodani M. Sustained-release tablet containing buffer substances which releases the active agents independent of the $\mathrm{pH}$ of the dissolving medium. W.O. Patent1987/006130. 1987. 
9. Doherty C, York P. Microenvironmental $\mathrm{pH}$ control of drug dissolution. Int J Pharm. 1989;50:223-32.

10. Farag Badawy SI, Gray DB, Zhao F, Sun D, Schuster AE, Hussain MA. Formulation of solid dosage forms to overcome gastric $\mathrm{pH}$ interaction of the factor Xa inhibitor, BMS-561389. Pharm Res. 2006;23:989-96.

11. Thoma K, Zimmer T. Retardation of weakly basic drugs with diffusion tablets. Int J Pharm. 1990;58:197-202.

12. Streubel A, Siepmann J, Dashevsky A, Bodmeier R. pHindependent release of a weakly basic drug from water-insoluble and -soluble matrix tablets. J Control Release. 2000;67:101-10.

13. Espinoza R, Hong E, Villafuerte L. Influence of admixed citric acid on the release profile of pelanserin hydrochloride from HPMC matrix tablets. Int J Pharm. 2000;201:165-73.

14. Rao VM, Engh K, Qiu Y. Design of $\mathrm{pH}$-independent controlled release matrix tablets for acidic drugs. Int J Pharm. 2003;252:81-6.

15. Tatavarti AS, Mehta KA, Augsburger LL, Hoag SW. Influence of methacrylic and acrylic acid polymers on the release performance of weakly basic drugs from sustained release hydrophilic matrices. J Pharm Sci. 2004;93:2319-31.

16. Siepe S, Lueckel B, Kramer A, Ries A, Gurny R. Strategies for the design of hydrophilic matrix tablets with controlled microenvironmental pH. Int J Pharm. 2006;316:14-20.

17. Tatavarti AS, Hoag SW. Microenvironmental $\mathrm{pH}$ modulation based release enhancement of a weakly basic drug from hydrophilic matrices. J Pharm Sci. 2006;95:1459-68.

18. Mooney KG, Mintun MA, Himmelstein KJ, Stella VJ. Dissolution kinetics of carboxylic acids. I: Effect of $\mathrm{pH}$ under unbuffered conditions. J Pharm Sci. 1981;70:13-22.

19. Serajuddin ATM, Jarowski CI. Effect of diffusion layer $\mathrm{pH}$ and solubility on the dissolution rate of pharmaceutical acids and their sodium salts. II: Salicylic acid, theophylline, and benzoic acid. J Pharm Sci. 1985;74:148-54.

20. Bi M, Kyad A, Li L, Avarez-Nunez F, Alvarez F. 2008. Effect of nucleation inhibitors in preventing precipitation of a model acidic drug molecule AMG 009. http://www.aapsj.org/abstracts/ AM_2008/AAPS2008-003045.pdf. 